\title{
Disclosure of Social-Economic Value in the Social Enterprise. Stimuli from an Italian Multiple Case Study
}

\author{
Antonietta Cosentino ${ }^{1}$ \\ ${ }^{1}$ Department of Law and Economics of Productive Activities University of Rome La Sapienza, Via Castro \\ Laurenziano, 9 - 00161 Rome, Italy \\ Correspondence: Antonietta Cosentino, Department of Law and Economics of Productive Activities University \\ of Rome La Sapienza, Via Castro Laurenziano, 9 - 00161 Rome, Italy.
}

\author{
Received: April 29, 2020 \\ Accepted: May 18, 2020 \\ Online Published: May 20, 2020 \\ doi:10.5539/ibr.v13n6p53 \\ URL: https://doi.org/10.5539/ibr.v13n6p53
}

\begin{abstract}
The growing interest in the financial, social and environmental sustainability of all organizations as a whole, as well as the growing sentiment for their responsibility towards the community, lead organizations to face the challenge of evaluating and communicating their non-financial performance through the social accounting. The issue assumes a peculiar meaning within social enterprises (SEs) aimed at pursuing the general interest. In these organizations, the disclosure of the value created for both internal and social stakeholder raises to rank of survival condition because the development, reputation and credibility of the SEs are closely linked to the institution's ability to reach and communicate externally the social value created. This work aims to highlight the peculiar resources of the SEs and demonstrate that, in most cases, they allow SEs to achieve financial sustainability. Social and economic value will be assessed and the share of income that cannot be distributed, regardless of the relevant regulatory provisions, will be emphasized. To achieve these goals, a multiple case study is used to measure the value added distributed to internal and external stakeholders by adapting Mook model to SEs. The results show that volunteering and donations contribute not only to the social value generated by SEs but to their economic sustainability as well, being considered as the engine of development of the economic system as a whole. This paper contributes to the literature by focusing on the contribution of liberalities and volunteering to consolidate the financial structure of the SE and to development of the economic system as a whole.
\end{abstract}

Keywords: social enterprise, social accounting, social sustainability, financial sustainability, income

\section{Introduction}

The theme of social accounting has been widely discussed in literature, and many reporting tools of social and environmental performances are used in practice. Related to conventional financial accounting, social accounting is a new interdisciplinary field that emerged in the 1970s following pressure from Economics scholars who were reconsidering the role and purpose of companies. In general, this was due to the growing interest in sustainability and organizational responsibilities towards society, which pushes organizations - public and private (Pollifroni, 2013), profit and non-profit (Mook, Richmond \& Quarter, 2009) - to face the challenge of evaluating and communicating their economic sustainability and non-financial performance (Crucke \& Decramer, 2016).

The first studies on social accounting focused on the impact of economic activities on the environment, but they later extended to the broader area of social aspects. Although, social accounting was born as environmental accounting (Hopwood, 2009) and later became social. Social accounting is based on the critique of the limitations of financial accounting, especially with regard to the limited range of items considered by it, its exclusion of non-monetised items, and its focus, which excludes internal and external stakeholders such as employees, users or consumers, community, government and volunteers (Lehman, 1995). Indeed, traditional accounting is based on the perspectives and interests of shareholders and other financing providers (Richmond, Mook \& Jack, 2003; Unerman, Bebbington and O'Dwyer, 2010). Social accounting can be defined as "a systematic analysis of the effects of an organization on its communities of interest or stakeholders, with stakeholders' input as part of the data that are analysed for the accounting statement" (Quarter, Mook \& Richmond, 2003, p. 3).

The consideration, on the one hand, of a wider system of values than that provided by monetary quantities obtained through exchanges (Benos, Kalogeras, Wetzels, De Ruyter \& Pennings, 2018) and, on the other, the focus on a wider concept of value than the one expressed by the economic outturn (Ebrahim \& Rangan, 2014) has led to the 
reconfiguration of traditional accounting statements. The latter do not assign monetary values to quantities that are not derived from exchanges, such as inconsistencies and inequalities (Gray, 2002) meaning those for which it is not possible to detect an exchange-value but only a use-value. Later, real evaluation methods of the economic and social impact generated on internal and external stakeholders were developed, leading to a further transformation of the entire external communication system of enterprises (Lewis \& Unerman, 1999).

The prevalent literature dealing with social accounting is focused on profit-oriented business (Clarke-Sather, Hutchins, Zhang, Gershenson \& Sutherland, 2011), focusing on enterprise's performances deriving from the increase in trust stemming from social communication (Del Baldo, 2012) and have analysed the indicators used in current international practices for the ethical evaluation of companies (Pollifroni, 2013).

The issue of disclosure of social performance also concerns public sector (Adams, Muir \& Hoque, 2014; Dal Mas, Massaro, Lombardi, \& Garlatti, 2019) as well as non-profit organizations (NPOs) (Mook, Richmond \& Quarter, 2003; Mook et al., 2009; Richmond et al., 2003), and SEs (Crucke \& Decramer, 2016; Benos et al., 2018). SEs are social mission-oriented organizations (Defourny \& Nyssens 2014) that carry out a systematic entrepreneurial activity (production and exchange of goods and /or services) in order to satisfy the needs of general interest that are not satisfied neither by the state nor by profit oriented enterprises (Kerlin, 2009). In SEs, the income represents a means not the purpose of the activities (Dees \& Anderson, 2006). Recent studies have provided a complete dashboard for evaluating the performance of SEs which harmonizes socio-economic aspects and allows to classify the basic components of the evaluation process (Manetti, 2014; Bagnoli \& Megali, 2011; Andreaus \& Costa, 2014), but less attention was paid to the limits of traditional accounting to account for the economic sustainability of SEs in the medium-long term.

This study aims to fill the gap by focusing on the disclosure accounting system in the SE. Through a multiple case study (Yin, 2014), the analysis will be built on a value added statement developed by Mook (Richmond et al., 2003) to which some adjustments have been made in accordance with the paper aim. The statement obtained will be tested on a sample of 239 Italian SEs. Finally, emphasis will be placed on internal resources that cannot be distributed to stakeholders. The latter is a novel approach that can contribute to literature and practice focusing on the process of creating added value and income within SEs.

This paper aims to achieve the following research objectives:

1) to highlight the peculiar resources on which the SEs can count;

2) to demonstrate that, in many cases, donations, in cash or another types (first of all the volunteering), not only allow SEs to achieve financial sustainability, but can be considered indicators of the company's effectiveness;

3) to assess the added value distributed to internal and external stakeholders of the SEs analysed;

4) to underline the share of income that cannot be distributed regardless of the regulatory provisions in this regard.

The results show that volunteering and donations are valuable resources in SEs like in donative organizations (foundations or charities). They contribute to both social value generated and economic sustainability of the initiatives. Indeed, without the contribution of volunteers and donations, the medium-long term economic sustainability of the less structured SEs would be compromised. Additionally, the free resources adequately used by the SE in the course of one's activities of general interest become an engine for the development of the economic system as a whole. This research contributes to the literature by focusing on the contribution of liberalities and volunteering to consolidate the financial structure of the SE and to development of the economic system as a whole.

The paper is structured as follows. Section 2 reviews the theoretical background to the main issues. Section 3 points out the research methodology and the results from empirical research. Finally, section 4 sets out the conclusions and implications, along with the limitations.

\section{Literature Review}

\subsection{Social Accounting}

Social accounting emerged in the 1970s as a straight criticism to traditional accounting, which did not reflect the impact of the firm on the internal and external stakeholder or environment since the value of its activities came only from markets measures. Other aspects such as the consumers or workers' well-being or the pollution originated by production activities are ignored even if they influence firms' reputation and their performance. In addition, traditional accounting is designed to accomplish the needs of the owners, managers and investors and this is 
mainly due to the traditional vision of the company (Baldarelli, Cosentino, Del Baldo, Magistro, 2018). In the ethical accountability business models, there is a "bidirectional link between traditional accounting information and the ethical dimension of the company" (Pollifroni, 2017, pp. 3-4) since the ethical dimension is valued in the accounts and is part of the same process of preparing the financial statements. In the latter case, the accounting data would be conditioned directly by the ethical profile of the company, which - as a result - would no longer be subject to a separate analysis carried out in documents separate from the financial statements (Pollifroni, 2017).

Initially, the interest of accounting scholars has been quite limited and concentrated on profit-oriented business (Bebbington, Gray \& Owen, 1999). The scholars have stressed the need to investigate and improve accounting changes as a tool for suggesting some more complex socio-political issues, as well as an economic basis for accounting practice (Hopwood, 2009).

Social accounting can be defined as "a systematic analysis of the effect of an organization on its communities of interest or stakeholder (...) It includes stakeholder input as data from which the accounting statement is prepared" (Mook, Handy \& Quarter et al., 2007, p. 41). In this way, the stakeholders are involved in the process of an ongoing organizational change (Mook et al., 2007). Social accounting aims to extend the range of criteria to measure company performance. Social accounting changes the perspective of analysing the company, embracing a perspective that observes as the inside of company as its surrounding environment, expanding the audience to which corporate communication is directed (Pollifroni, 2012). The social accounting advocates for a triple bottom line of financial, environmental, and social returns (Elkington, 2013). Some scholars used the new perspective to find ways in which social and environmental accounting research could be encouraged managerial behaviour change within the capitalist system (Gray, Owen, \& Adams, 1996). Others argued that the reporting process, behaviour of internal stakeholder and manager and corporate culture and vision play an important role in determining the extent of accountability discharged through corporate disclosures (Parker, 2005; LarrinagaGonzalez \& Bebbington, 2001; Baldarelli \& Del Baldo, 2018). By revisiting the concept of sustainable development and corporate social responsibility, a series of activities "with an ethical value" can be identified, intended to affect the internal structural architecture of the company and the external environment - essentially in terms of corporate reputation - capable of affecting management, organization, financial results and corporate reporting (Pollifroni, 2017, pp. 24 and 47).

Social accounting redirects traditional accounting to a large set of variables and social interests, which, with various techniques and methodologies, are included in the company reporting. Scholars and practitioners have drawn up several attempts to integrate economic and financial accounting with social accounting. For example, Triple Bottom Line (Elkington, 2013), Blended Value Accounting (Nicholls, 2009), Social Environmental Accounting (Richmond et al., 2003; Gray, 2002), Social Accounting (Bebbington et al., 1999; Global Reporting Initiative, 2018; Mook et al., 2003), Integrated Reporting (Demartini \& Paoloni, 2017; Dumay \& Dai, 2016; De Villiers, Venter \& Hsiao, 2017) are the most significant and widespread methods. Many studies focus on the different ways of calculating the surplus in corporations, particularly with regard to the role of labour in its production. Many of them resulted from the pressure from unions for higher earnings for employees (today the pressure is to maintain the number of workers), as a "replacement cost accounting" may help to protect earnings to be used for reinvestments. In the 1980s there was an increase in the interest, study and use of value added accounting, which demonstrated the high returns to labour and the much lower ones to capital (Ball \& Brown, 1968; Gabrovec Mei, 2002). Some stimuli about this topic come from the recently transposition of the European directive (2014/95/EU) in the national laws that requires listed companies, banks and insurance companies of certain size to draw up a non-financial statement, containing additional information on the environment, society, workforce, respect for human rights, active and passive anti-corruption measures. Non-financial information have to disclose in addition to the traditional annual accounts (La Torre, Sabelfeld, Blomkvist, Tarquinio \& Dumay, 2018).

\subsection{Social Accounting from the Perspective of Social Enterprise}

The new theoretical approaches of the social accounting not only concern about profit oriented business but also public enterprises (Grimsey \& Lewis, 2005) and non-profit organizations (NPOs) that make up the so-called social economy (Quarter et al., 2003). In the social economy are included all organizations "that have a social objectives central to their mission and practice" (Mook el al., 2007, p. 17) or who pursue social and economic objectives (Salamon \& Anheier 1996). SEs are included in this context and considered a distinct category of organizations, positioned between profit and non-profit ones (Dees \& Anderson, 2006). The concept of SE varies extensively in international literature, including a vast series of economic initiatives defined as social and different legal forms (Kerlin, 2009). They have a dual nature, which reflects both the implementation of social objectives and the market orientation. SEs do not pursue profit but the general interest (Borzaga \& Defourny, 2001) and non-profit distribution constraint is addressed in different ways. The entrepreneurial nature of SEs is declaimed trough 
commercial activities running. Compared to NPOs, SEs carry out entrepreneurial activities and they are market-oriented organizations with hybrid nature. It follows that the economic sustainability of SEs is guaranteed by revenues and not only by grants and donations like for the NPOs (Defourny \& Nyssens, 2014). Another feature of SE is their inclusive governance-ownership that reflects their social mission (Defourny \& Nyssens, 2014).

This approach complying the conceptualisation of SE developed by the EMES - International Research Network that may represent a framework based on the different social, political and economic "traditions" of the various countries (Defourny \& Nyssens, 2014). As effectively emphasised, the SE has a "problem-solving" nature and the activities it carries out have a social impact (Peredo \& McLean, 2006). Dees and Anderson (2006) have stressed this concept, referring to a previous work by Young (2013) according to which a distinctive characteristic of the SE is its ability to generate output and social impact rather than profit. Many studies underline that in the European context the concept of SE is not strictly connected to the prohibition on distributing profits and surplus (Young \& Salamon, 2002; EU, 2020). In fact, the social aims pursued and its governance are its distinctive features (Cosentino Bongiovanni, Cesari \& Di Stefano, 2017). The original management style of the SEs considers interests and goals of multiple categories of entities. Hence, partial income distribution on one hand, and straight relationships with the stakeholders on the other, allows see SEs as real "corporate labs", or centre where new enterprise and governance forms are trialled. The process of income generation has been scarcely analysed in literature. It was investigated as a tool for the development of SE (Epstein \& McFarlan, 2011), in its relationship to consumers (Hansmann, 1980) and under the lens of its non-distribution constraint (Andreaus \& Costa, 2014). It was neglect how the donations, necessary for many SEs to be economically sustainable, contribute to its formation. Additionally, there are currently no studies focused on an accounting process of income determination that considers the "hybrid" features of SEs (Doherty, Haugh and Lyon, 2014).

Traditional accounting limitations for representing the results of SEs are evident. First, they ignore significant inputs (for example volunteer labour) which instead characterize many entities. On the other hand, they do not take into account many outputs, in particular social and environmental ones that do not pertain to market exchanges (Mook \& Quarter, 2006). Furthermore, the conventional accounting framework is unable to summarise, represent and evaluate the overall value achieved (Grieco, 2015). Scholars and practitioners point out that a system for monitoring the results of NPOs, in general, must be based on ascertaining their financial performance and the achievement of their social goals, the so-called mission-based performance (Epstein \& McFarlan, 2011). The former is attributable to profitability, liquidity, adequacy of equity and efficiency (Giampaoli, Ciambotti \& Bontis, 2017). The latter can be expressed in terms of revenue growth, efficient allocation of assessable (or, rather, measurable) resources and ability to attract and produce financial resources (Bowman, 2011). Gray et al. (2006) have found that the essence of accountability lies in the relationships between the organisation and the society and/or stakeholder groups of interest. Andreaus and Costa, (2014) propose an integrated accountability model that integrates mission report, social and environmental report, and income statement and balance sheet, focusing on NGOs and charities. Brown and Moore (2001) compare the international non-government organizations in terms of accountability relationships and priorities. Other studies focus on assessing the social performance of SEs through the Social Return on Investment (SROI) model (Urban, 2015) clarifying the strengths and weaknesses of blended value accounting (Manetti, 2014).

The debate about the tools that could bring out the creation of value for social stakeholders has been of great interest (Warheit, Buhl and Bell, 1978; Richmond et al., 2003; Quarter et al., 2003; Parker, 2005; Nicholls, 2009; Mook et al., 2003; Manetti, 2014) as well as the contribution of volunteering for creating this value (Quarter et al., 2003; Mook et al., 2009). Less attention has been paid to the capacity of traditional accounting to highlight the economic and financial sustainability of the SE. The traditional approach to accounting has attracted criticism based upon its assumptions. In fact, the traditional approach is unable to represent a wide range of stakeholders affected by the organizations' activities. Some scholars argue that accounting should serve as an intermediary between (and within) organizations and society (Lehman, 1995).

Financial equilibrium only was emphasized as a means of achieving corporate objectives, which are and remain social (Deakin \& Morris, 2012), and it must be constantly monitored through a complex multidimensional evaluation, whose measurement tools are not unanimously shared, mainly because of the subjectivity connected to the evaluation of many intangible activities, primarily human and relational capital (Cosentino et al., 2018). Bagnoli \& Megali (2011) have stressed the need to implement a control system spread over three items: financial performance (e.g. economic and social value added), social effectiveness (achievement of objectives) and social legitimacy, essentially expressed through compliance with the law. Mook et al. (2003) have proposed the so-called "economic-social added value" (EVAS). They argued that performance of NPOs must be measured through a value-added income statement, which highlights the wealth created not only for the "owner" but for the broader spectrum of stakeholders: 
employees and collaborators, communities and financiers (Mook et al., 2009). The VAES (economic and social value added) proposed by Bagnoli and Megali $(2011$, p. 152) seems to be inspired by the latter framework even if the authors add other schemes to represent social effectiveness and institutional coherence.

The social accounting project for NPOs can be used as a pathway towards innovative practices increasing organisational transparency (Grieco, 2015). The reasons that determine a growing demand for information are linked, on the one hand, to the need to report to the stakeholders on the activities performed, and this is true mainly for SEs and generally for the third sector, especially in order to attract resources from the outside and improve the trust of external stakeholders (Cosentino et al., 2018). On the other hand, more recently there has been a need to shift the focus of reporting activities and procedures from accountability to the more specific and widespread concept of impact. Funders, mainly lenders, government and the community in general, require NPOs to demonstrate their results in addressing complex social issues such as poverty and inequality.

Various scholars underline this research stream. The perspective of the authors is focused on the fundamental role of the volunteers in creating social value (Quarter et al., 2003; Mook et al., 2003; 2009; Handy, Mook and Quarter , 2008). They showed that "a significant amount of the value generated by non-profits comes from volunteer contributions, which, because they are not exchanged in the market, are not reflected in conventional accounting statements" (Mook, Sousa, Elgie \& Quarter, 2005, p. 402) and that "for organizations that do not have shareholders in the same sense as profit-oriented businesses, an income statement has a more limited role" (Mook et al., 2007, p. 58). The topic is very interesting but has been widely discussed with reference to charities and philanthropic entities.

Table 1 shows the main implications deriving from the social accounting criticisms emerged from the literature review.

Table 1. Literature on social accounting

\begin{tabular}{|c|c|c|c|}
\hline Contributions & Topic & Main contents & $\begin{array}{l}\text { Implications deriving from } \\
\text { social accounting criticism }\end{array}$ \\
\hline $\begin{array}{l}\text { Bebbington et al., } 1999 \\
\text { Clarke-Sather et al., } 2011 \\
\text { Gray, } 2002 \\
\text { Mook et al. 2003, 2007, } \\
2009\end{array}$ & $\begin{array}{l}\text { Social accounting } \\
\text { criticism }\end{array}$ & $\begin{array}{l}\text { TA does not reflect the impact of the } \\
\text { firm on the internal and external } \\
\text { stakeholder or environment } \\
\text { The value of the firms comes only } \\
\text { from markets measures } \\
\text { The intangible effects of corporate } \\
\text { activities on stakeholders are not } \\
\text { considered }\end{array}$ & $\begin{array}{l}\text { Intangible aspects such as the } \\
\text { consumers or workers' } \\
\text { well-being or the pollution } \\
\text { originated by production } \\
\text { activities are included into the } \\
\text { accounting because they } \\
\text { influence firms' reputation and } \\
\text { performance }\end{array}$ \\
\hline
\end{tabular}

TA does not assign monetary values to quantities that are not derived from exchanges, such as inconsistencies and inequalities TA excludes internal and external stakeholders such as employees, users or consumers, community, government and volunteers

Richmond et al., 2003

Unerman et al., 2010

Gray et al., 2006

Social accounting TA is designed to accomplish the criticism needs of the owners, managers, funders and investors

Quarter et al., 2003

Mook et al., 2006

Mook et al., 2007
Social accounting

New accounting perspective includes outputs not pertain to market exchange
Hopwood, 2009

Gray et al., 1996

Lehman, 1995
Critical accounting

Accounting should serve as an intermediary between and within organizations and society
The essence of accountability lies in the relationships between the organization and the society and/or stakeholder groups of interest

Systematic analysis of the effects of an organization on its stakeholders are carried out Stakeholders' input are included in the data

Social and environmental outputs are analyzed for the accounting statement

Stakeholders are involved in the process of an ongoing organizational change

The novel approach encourages more complex socio-political issues as well as an economic basis for accounting practice 
Pollifroni, 2013

Crucke and Decramer, 2016

Pollifroni, 2017

Pollifroni, 2012

Bagnoli and Megali, 2011

Mook et al. 2003

Mook et al., 2009

Richmond et al., 2003

Benos et al., 2018

Ebrahim and Rangan, 2014

Lewis and Unerman, 1999

Manetti, 2014;

Bagnoli and Megali, 2011;

Andreaus and Costa, 2014
Social accounting New indicators can be used for the indicators

Ethical accountability

ethical evaluation of companies

A series of "ethical value" activities affects the internal structural architecture of the company and the external environment

Social accounting tools in NPOs and SEs

Social accounting tools in NPOs and SEs

Social accounting tools in NPOs and SEs

Social accounting in SEs

control system needs to spre over three items: financial performance, social effectiveness and social legitimacy

Performance of NPOs are disclosed through a value-added income statement, which highlights the wealth created for a broader spectrum of stakeholders

Wider system of values than that provided by monetary quantities obtained through exchanges is designed

Complete dashboard for evaluating SEs performance which harmonizes
Social and environmental accounting could encourage managerial behavior change within the capitalist system

The firms face the challenge of evaluating and communicating their economic sustainability and non-financial performance

The ethical dimension is valued in the accounts and is part of the process of drafting the financial statements.

An ideal bidirectional connection between traditional and social/environmental accounting can be assumed Innovative practices increasing organizational transparency socio-economic aspects and allows to classify the basic components of the evaluation process is showed
Traditional accounting limitations for representing the results of NPOs are removed

A wider concept of value than that expressed by the economic outturn is introduced

Evaluation methods of the economic and social impact leads to a further transformation of the entire external communication system Greater attention from public opinion, lenders, donors and government to the impact generated by the SEs

Two main weaknesses emerged from the literature review:

- little attention was paid both to the contribution of the volunteers and the limitation of traditional accounting associated with the SEs. Both aspects are fundamental for assessing the economic sustainability of the SE in the medium-long term;

- the market-oriented nature of SE makes it able to achieve an income to which donations and volunteers have contributed. Traditional accounting is unable to underline the share of income that cannot be distributed regardless of the regulatory provisions in this regard.

This paper aims to bridge the gaps by drawing inspiration from to Mook's model (Richmond et al., 2003). The topic is interesting because traditional accounting is not sufficient and adequate to represent the multifaceted reality of the SEs and other tools must be used to disclosure their financial and social performances and to give prove of the value created for the social stakeholder. The SEs represent a very important social actor. Recent research estimates that in Italy operates an amount of 102,461 SEs (1,694 per million inhabitants) that employs 894,800 people. The economic turnover 37.3 billion Euros. Referring to European context 13.6 million Europeans work today in the SEs (EU, 2020, pp. 106-107). Their development will be central to overcome the socio-economic crisis following Covid-19 and underway at the time of the completion of this study.

\section{Research Method and Context}

\subsection{Research Design}

In order to achieve the aims of this paper, a qualitative multiple case studies research method was used (Berg, 2007; Yin, 2014). It is particularly appropriate to investigate how a phenomenon has been built up through a "contemporary set of events over which the investigator has little or no control" (Yin, 2014, p. 913). Additionally, the case study approach allows the researchers to analyse the theories recognized in the literature review phase in a real-life context. Case study research is also useful to provide a freshness of perspectives to a previously researched topic and complement the existing theories identifying new elements trough the in-depth analysis of the 
phenomenon at hand (Yin 2014). Accordingly, starting from the case selection process contemplated by Eisenhardt and Graebner (2007), the cases study were chosen as representative and leading cases compliant with paper aim (Patton, 1990; Stake, 2013).

The data were examined using the lens of the social accounting and the analysis will be built on a value added statement (Mook et al., 2003). The original framework was adapted to the purposes of this study and tested on the restricted sample of 239 Italian SEs. Building the model on EVAS developed by Mook (Mook et al., 2003; 2007; 2009), some adjustments have been made in accordance with the paper's aim. Finally, an integrated income statement (IIS) has been proposed. The IIS distinguishes from Mook's framework for following main aspects: (a) every donations of time and money are extract to the value added, (b) the statement will be tested on SEs instead donative organizations and (c) the social and economic statement proposed emphasizes internal resources that cannot be distributed to stakeholder. The latter is a novel approach that can contribute to literature and practice focusing on the process of creating value added and income within SEs.

The model of Mook and colleagues focus on the donative organizations thus does not consider the hybrid nature of the SEs: the latter are market-oriented, a significant part of their resources comes from public contributes, and donative resources (money or labour) usually integrate the revenues. Because of these, the donative resources must be extracted from the value added created but contribute to the social value generated. Furthermore, in IIS will be distinguished the part that cannot be distributed to stakeholder, with the exception of workers.

\subsection{Research Protocol}

To achieve the paper aim, the research methodology was structured in four phases (Jervis \& Drake, 2014):

(1) the first phase focused on literature review and three main topics compliant with the paper aims are undertaking: social accounting, critical accounting, ethical accountability;

(2) the second phase aimed to seek the connections between selected topics and ideal types of case study based on scientific literature reviewed. Thus,

(3) during third and explorative phase, information were collected from secondary sources, such as social media, specialist newspapers and websites and "Alfa Cooperative Group" (ACG) (invented name to guarantee the anonymity of the group) is chosen as "polar type" (Eisenhardt \& Graebner, 2007);

(4) lastly, during the fourth phase, primary data were collected and a restricted sample useful to the paper aim is considered.

To support the analysis, a research protocol was implemented (Yin, 2014) to validate the results The research protocol and first results are summarized in Table 2.

Table 2. Research protocol and first results

\begin{tabular}{|c|c|c|c|}
\hline Stages of the research & Sources & Typology & Results \\
\hline $\begin{array}{l}\text { Select topics relevant and compliant to } \\
\text { the paper aims }\end{array}$ & Secondary data & Scientific literature & $\begin{array}{l}\text { Social accounting, } \\
\text { Critical accounting, } \\
\text { Ethical accountability } \\
\text { New accounting perspectives } \\
\text { and more suitable tools to } \\
\text { express the value created by } \\
\text { the SEs }\end{array}$ \\
\hline $\begin{array}{l}\text { Seek the connections between selected } \\
\text { topics and ideal type of case study }\end{array}$ & Secondary data & Scientific literature & $\begin{array}{l}\text { Significant presence of } \\
\text { donations, liberalities and } \\
\text { voluntary work } \\
\text { Focus on SEs to bridge the } \\
\text { literature gap } \\
\text { Extend the analysis on a } \\
\text { large number of SEs } \\
\text { widespread in national } \\
\text { territory }\end{array}$ \\
\hline $\begin{array}{l}\text { Identify a target SEs and select accessible } \\
\text { and suitable case studies }\end{array}$ & Secondary data & $\begin{array}{l}\text { Social media } \\
\text { Specialist newspaper } \\
\text { Web site }\end{array}$ & ACG \\
\hline $\begin{array}{l}\text { In-depth analysis of significant case } \\
\text { studies }\end{array}$ & $\begin{array}{l}\text { Primary data } \\
\text { Secondary data }\end{array}$ & $\begin{array}{l}\text { Interviews with apical } \\
\text { and middle managers } \\
\text { Content analysis of } \\
\text { annual reports }\end{array}$ & $\begin{array}{l}\text { an amount of } 239 \text { SEs joined } \\
\text { to ACG are selected and } \\
\text { investigated }\end{array}$ \\
\hline
\end{tabular}




\subsubsection{Sampling Procedures}

This research started from an original sample of 598 SEs, distributed throughout Italy, and belonging to the ACG, a network of territorial consortia, which coordinates cooperatives and SEs activities. Actually a total amount of 701 SEs are joined in ACG, and there are 42,000 workers employed but the dataset was available only for 598 of them. The original sample has been divided into classes based in two parameters: other revenues and volunteer members.

The purpose of the clustering is to identify the groups of SEs for which the presence of donations and liberalities (inscribed in the item "other revenues" as shown in the interviews), and voluntary work could have a greater potential impact on their financial results. Going a step further, units of data and variables were grouped simultaneously (Anderberg, 1973), and a narrow cluster consisting of SEs having both variables was obtained.

The restricted cluster is made up of 239 SEs active both in the most traditional fields of personal care (minors, elders, immigrants, people with disability) and in emerging and frontier sectors (environment, living, technology, art and culture, tourism, support for the work). For SEs of the restricted sample the accounting system is structured and homogeneous. Data was collected from their annual reports and internal accounting. SEs analysed adopt the same balance sheet template provided for profit oriented companies without drafting the explanatory notes.

\subsection{Measurement Approaches}

The available data did not allow to have all the useful information for the paper aims, thus it was necessary integrate the analysis through individual semi-structured interviews (Spencer \& Ritchie, 2002) which were conducted to two managers of the ACG. The selection criteria of the interviewees were the following:

(1) independent bodies: the interviewees are employees of the ACG and do not have subordinate employment relationships with the SEs investigated;

(2) competence with respect to the research objectives: interviewee 1 (male) managed the entire process of collecting balance sheet data of the SEs belonging to ACG; interviewee 2 (female) is responsible for the group's projects and has contacts with the managers of SEs associate with ACG;

(3) broad vision of the entire organizational structure of the group: the position of the interviewees within the central organizational structure made it possible to have a systemic vision of the realities which, given their number and location throughout the Italian territory, were not easily reachable;

(4) gender equality: SEs are very sensitive to the issue of gender equality. This aspect has also been taken into account in the selection of interviewees.

The interviews had been started on November 2018 and ended on July 2019, and lasted on average 40 minutes each. The details of them are summarize in the Table 3. The semi-structured interviews involved eight open questions showed in the Table 4 while Table 5 summarize data collection and analysis.

Table 3. Interview details

\begin{tabular}{llll}
\hline Interviewees & Role & Department & Reference dates \\
\hline Interviewee 1 & Accounting Manager & Research and Training Office & November 2018 \\
& & & December 2018 \\
Interviewee 2 & Middle Executive Manager & Project Management & November 2018 \\
& & & January 2019 \\
& & July 2019 \\
\hline
\end{tabular}

Table 4. Main questions

\begin{tabular}{ll}
\hline No & Main questions \\
\hline 1 & General information useful for clustering SEs \\
2 & What accounting standards are used by the group's SEs? \\
3 & Do SEs prepare a value-added income statement? \\
4 & Does the internal accounting system keep donations separate from other revenues? \\
5 & Is the contribution of the volunteers valued in any way? \\
6 & Are the volunteers who work within the companies occasional volunteers or voluntary members? \\
7 & What incidence do donations and the contribution of volunteers have on the sustainability of SEs? \\
8 & According to your experience what is the contribution of volunteers to the development of SEs? \\
\hline
\end{tabular}


Table 5. Data collection and data coding

\begin{tabular}{lll}
\hline Methodology & Source & Typology \\
\hline Semi-structured interviews & Primary data & Interviews with Apical Figure and Middle Manager \\
Content analysis & Secondary data & Annual report (year 2017) of 239 SEs \\
& & Articles in the press, online and printed \\
& AGC's corporate website \\
\hline
\end{tabular}

\subsection{The Reference to Mook's Model. Similarities and Differences}

IIS highlights the stages of economic and social value creation by the activities of the SEs. The economic outcome realised by SE will be divided into more areas such of them will show the income of the various participants in the production process, that is, using a value-added approach to disclose revenues, expenses, and the final result (Bagnoli \& Megali, 2011). In addition, it will be represented the impact generated by the volunteers work (Mook et al., 2007) according to procedures that are sufficiently objective and hence suitable to represent a reliable result.

According to the value-added statement framework, IIS uses information from the financial accounts to calculate the value added by the SEs through the transformation of externally purchased goods and services. Additionally, it looks beyond income to encompass ownership and includes the wealth created for a wider group of stakeholders (Richmond et al., 2003). Unlike other models proposed by scholars and practitioner (e.g. Bagnoli \& Megali, 2011; Mook et al., 2003; 2009; Handy et al., 2008), in the IIS the "other revenues" are extrapolated from the production value because the interviews have pointed out that the item includes donations and liberalities. Their inclusion in the economic added value would have been incorrect.

\section{Results}

\subsection{The Results from Content Analysis (Annual Reports)}

First data analysis results are summarized in the Figure 1. The analysis of the financial statements of the 598 SEs, for which the data were available, showed that 239 SEs (40\% of the primary sample) have the item "other revenues" other than "revenues from sales", entered in income statement (a). They represent our relevant sample (restricted sample). An amount of 204 SEs achieved an income in the 2017 year ( $85 \%$ of the sample) while 35 of them (15\%) had a loss.

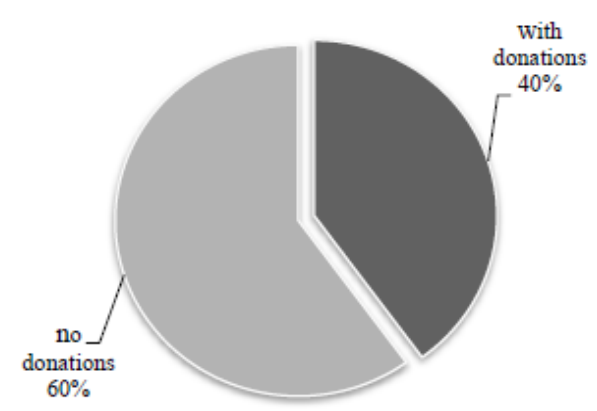

(a)

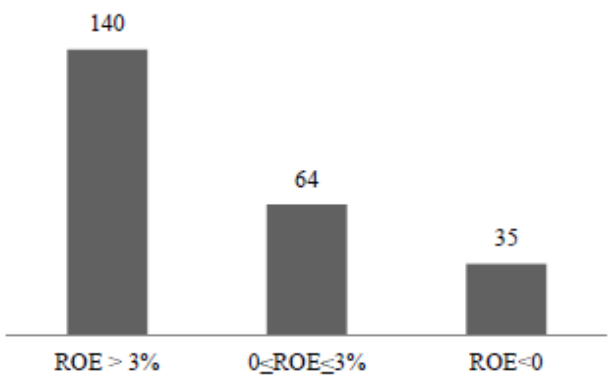

(c)

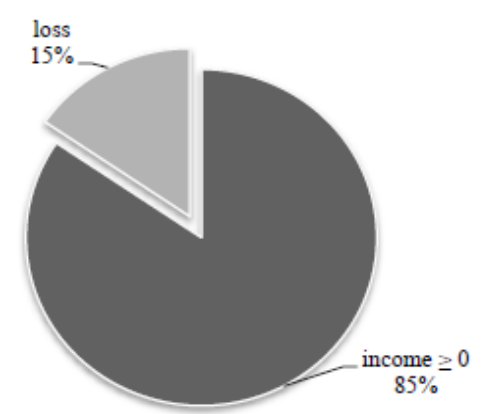

(b)

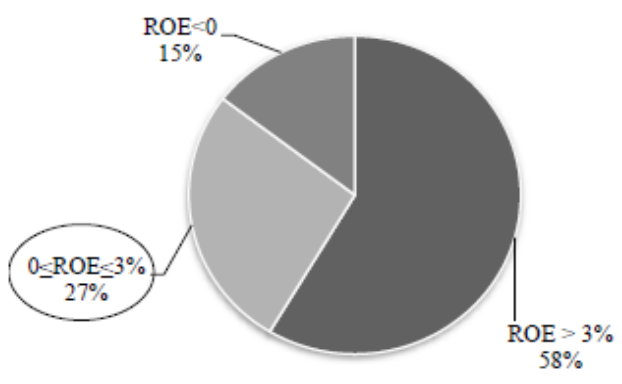

(d)

Figure 1. Data analysis: (a) original sample: percentage of SEs that received donations; (b) restricted sample (only SEs that received donations): percentage of SEs that achieved an income or not; (c) restricted sample: number of SEs distinguished by ROE size; (d) restricted sample: percentage of SEs distinguished by ROE size 
Also relevant for the purposes of this research is the data relating to the number of SEs that have achieved a ROE (return on equity) greater than zero and which therefore potentially can distribute income within the limits imposed by law. According to Italian law, this limit must be contained within approximately 3\% (rate of postal savings bonds increased by $2.5 \%$ ) of the net capital, less the obligatory provisions. This point will be emphasized later in sub-section 4.1.1.

Moving on to analyse the presence of volunteers, the internal documents of the 598 SEs for which data were available showed that the $43 \%$ of the SEs investigated, for a total amount of 258 cases, have volunteers who offer their systematic activity to achieve social goals. Only a case shows a number of volunteers greater than 100 (112 volunteers), which represents $21 \%$ of the total workforce (545 employees) in the SE analysed.

Table 6 shows in how many cases observed the volunteers operate stably. Five frequency classes were detected. Only in the $3 \%$ of the cases observed the number of volunteers is significant and ranges between 36 and 67 while in most cases it is irrelevant.

Table 6. Number of volunteers per case observed

\begin{tabular}{ccc}
\hline & Percentage of cases observed & Number of volunteers \\
\hline 34 & $1-3$ \\
& 30.5 & $4-9$ \\
& 25 & $10-20$ \\
& 7 & $21-35$ \\
\hline Total & 3.1 & $36-67$ \\
\hline
\end{tabular}

\subsubsection{The Results from the Restricted Sample}

At this point, after that data and variables were grouped simultaneously on base on the two significant variables (liberalities and volunteers), a narrow cluster consisting of SEs having both variables was obtained.

Table 7 shows the number of cases observed clustering according the incidence of the donations on the production value. Only in the 3 per cent of the cases observed, the impact of donations on turnover is significant and it ranges between 26 and 35 percent while in most cases it is irrelevant with a range between 1 and 5 percent. It is consistent with the characteristics of SEs in general.

Table 7. Incidence of the donations on the production value

\begin{tabular}{ccc}
\hline & Percentage of cases observed & Other revenues/Production value \\
\hline 0.70 & $0.01-0.05$ \\
\hline 0.12 & $0.06-0.09$ \\
0.08 & $0.10-0.15$ \\
0.06 & $0.16-0.25$ \\
& 0.03 & $026-0.35$ \\
\hline Total & 0.01 & Greater than 0.50 \\
\hline
\end{tabular}

Table 8 shows the clusters of SEs graded for economic results. In $16 \%$ of the cases observed the SEs have a loss, in $35 \%$ of cases the economic result is positive but limited (less than 10,000 Euros ). 
Table 8. Clusters of SEs graded for economic results

\begin{tabular}{cc}
\hline Percentage of cases observed & Profit or Loss \\
\hline $\begin{array}{c}0.16 \\
0.35\end{array}$ & loss \\
\hline 0.22 & $0-10,000$ \\
0.12 & $55,001-55,000$ \\
0.11 & $100,001-300,-30000$ \\
0.03 & $300,001-500,000$ \\
0.01 & $500,001-1,300,000$ \\
\hline
\end{tabular}

Data analysis revealed that in four cases there was a substantial break-even and a high incidence of donations (between 20 and 32 per cent of turnover). It follows that in the absence of donations, SEs would not have been economically sustainable. Only in three cases, very high incomes (over 250,000) correspond to a low incidence of donations (even it is not higher than 1\%). Figure 2 shows the results of the simple linear regression between net income and liberalities.

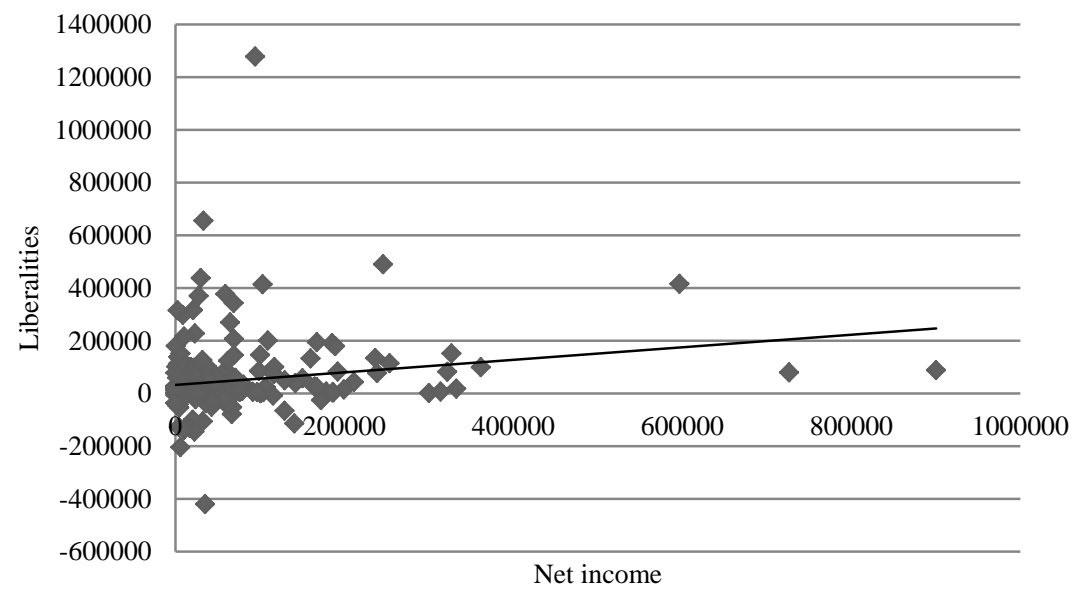

Figure 2. Simple linear regression between net income and liberalities

Another important parameter analysed has been the ROE. Its distribution over the observed cases is shown in Figure 3.-

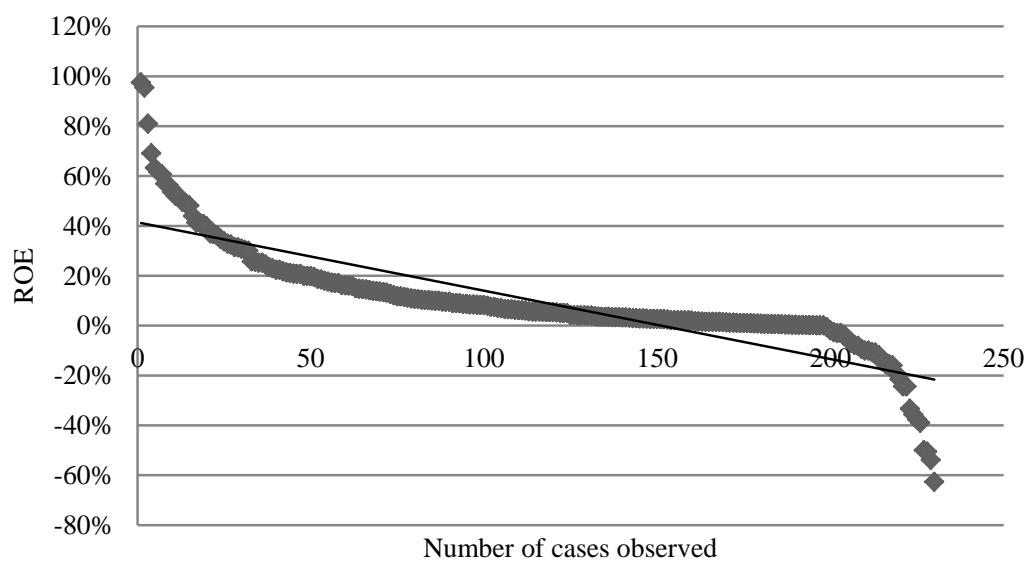

Figure 3. Linear distribution of ROE 
Nine cases were excluded from the figure because of their extraordinarily high or low ROE (over $100 \%$ or over $-100 \%)$ or because their equity was negative. The remaining data (230 SEs) are interesting because an amount of 204 SEs generates potentially distributable income within the limits allowed by Italian law (see also the previous Figure 1). Regarding this topic more details has been shown at the beginning of sub-section 4.1. Table 9 summarizes details about the latter provision.

Table 9. Relevant limits to the income distribution in the Italian SEs (cooperative or not)

\begin{tabular}{|c|c|c|}
\hline Income distribution or allocation & Social cooperative & Social enterprise \\
\hline Allocation to legal Reserve & $30 \%$ & More than $50 \%$ \\
\hline $\begin{array}{l}\text { Devote to mutual funds for promotion and } \\
\text { development of cooperation or social enterprise }\end{array}$ & $3 \%$ (duty) & $3 \%$ (voluntary) \\
\hline Revalue the capital & Up to the limit of inflation rate & Up to the limit of inflation rate \\
\hline $\begin{array}{l}\text { Refund the employees-shareholders for work } \\
\text { (rebates) }\end{array}$ & No limit & No limit \\
\hline Distribution to the shareholder & $\begin{array}{l}\text { Up to the limit of the rate on } \\
\text { public bonds plus } 2.5 \%\end{array}$ & $\begin{array}{l}\text { Up to the limit of the rate on } \\
\text { public bonds plus } 2.5 \%\end{array}$ \\
\hline
\end{tabular}

The reviewed literature widely demonstrated volunteering produces a significant part of the so-called social value added of the NPOs. Scholars have also handsomely demonstrated how to calculate the value of this important resource (Mook et al. 2007; Gaskin, 1999). A recent research regarding the Italian context (Guidi, Cappadozzi \& Fonovic, 2016) shows that volunteers dedicate half a day a week to those who need help in the field of social services, civil and health protection. Assuming that volunteers work for at least 4 hours a week, for 40 working weeks a year, this gives a total amount of 160 worked hours for each volunteer.

Table 10 shows the data useful for assessment of non-monetary inputs (volunteer work) joined with SEs of case study. The data are from the 2017 annual reports of the 239 SEs. Another information cannot be collected from internal accounting or financial statement was obtained through in-depth interviews.

Table 10. Data relevant to evaluation of non-monetary inputs

\begin{tabular}{lc}
\hline Relevance data & Amount / or value \\
\hline Total labour costs & $375,747,426$ \\
Average annual cost per employee & 19,612 \\
Number of employees & 19,159 \\
Number of volunteers & 2,628 \\
Average working hours per week & 40 \\
Volunteers' hours worked & 420,480 \\
Estimated value for each volunteer & $1,961^{*}$ \\
Overall estimated value for volunteers & $5,153,508$ \\
\hline
\end{tabular}

The value of the work rendered by volunteers (estimated value for each volunteer) was obtained by comparing the average annual cost per employee (calculated on an average of 40 working hours per week) to the hours each volunteer gives every week (4 hours). The equation (1) shows the result obtained:

$$
\begin{gathered}
19,612: 40=x: 4 \\
x=1,961^{*}
\end{gathered}
$$

Unlike other studies, the value of volunteering is estimated only on the basis of the average cost of workers employed in analysed case studies. The market value for personal growth and development is not valued (Mook, Richmond and Quarter, 2003, p. 291) as well as the unpaid contributions of the working members. Interviewee 2 points out:

\section{All members of the cooperatives, including the members of the board of directors, carry out several hours of unpaid work every day.}

Consequently, in this paper the value of voluntary work was underestimated. Figure 4 shows the results of the simple linear regression between number of employees and volunteers. 


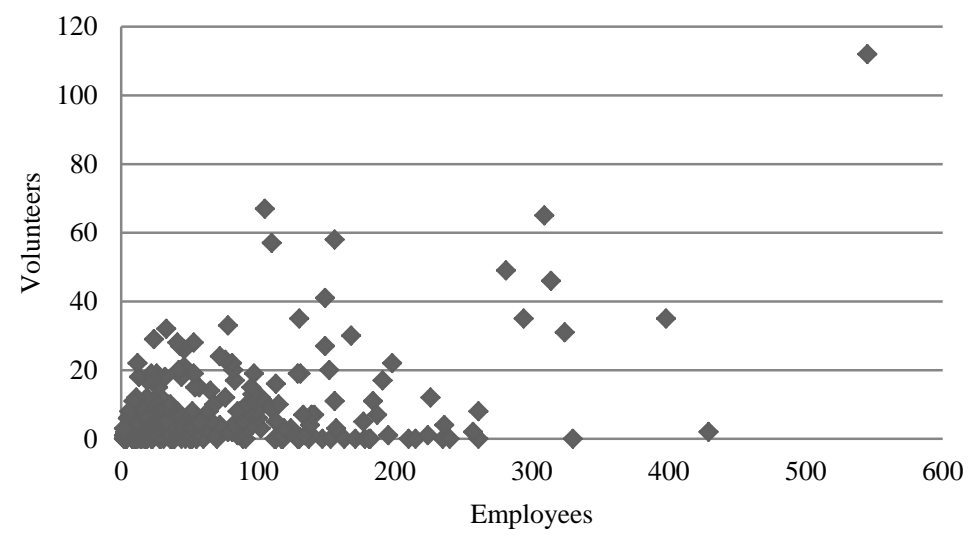

Figure 4. Simple linear regression between number of employees and volunteers

Table 11 shows the economic and social value added assesses for the ACG social enterprises analysed. The scheme offers a representation of the integrated income and can be called integrated income statement (IIS).

Table 11. IIS - Consolidated Economic and Social value

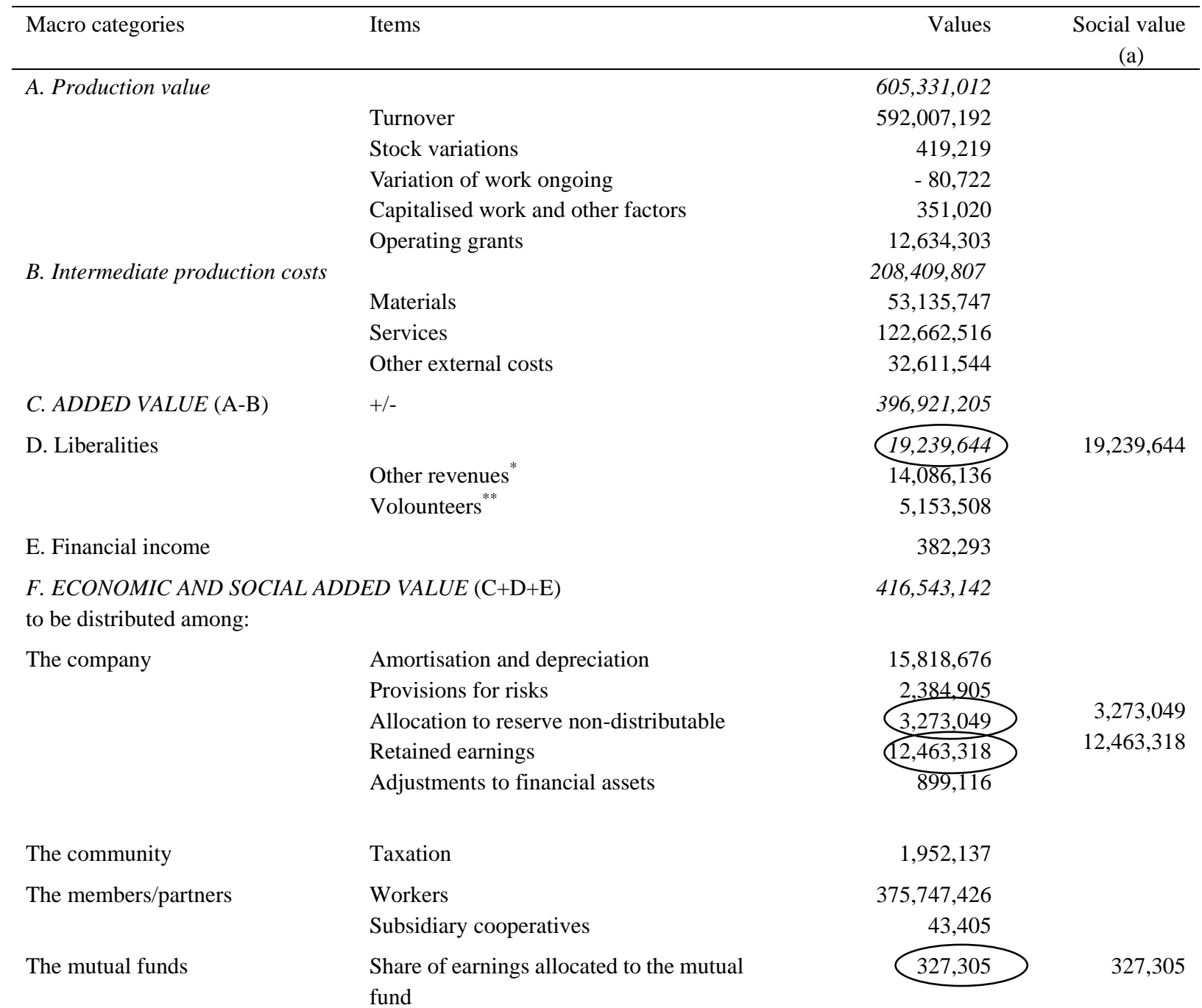




$\begin{array}{lrr}\text { The external funders } & \begin{array}{l}\text { Interests costs } \\ \text { Exchange losses }\end{array} & 3,623,124 \\ & 10,681 \\ \text { Economic and social added value distributed } & 416,543,142 \\ & \\ \text { Economic value }(F-D) \text { and Social value }(a) & 381,239,826 & 35,303,316\end{array}$

\subsection{Some Insights Taken from the Interviews}

The interviews were essential to analyse, classify and interpret the available data. Some details on them were provided during the presentation of the quantitative results. Other aspects useful for the paper purpose are shown below.

In the above IIS "other revenues" are extrapolated from the production value. Their inclusion in this area of the income statement makes sense when referring to profit oriented companies but it distorts the meaning of the production value when applied to SEs. In fact, both the managers interviewed point out that:

"[E]very SEs associate with ACG use the template provided for profit companies".

However, from the interviews it emerged that there is no great awareness of the usefulness of the value added income statement because this tool is neither widespread nor known. Its implementation would be incentivised. As interviewee 1 tells:

"[N]one of the SEs joined in ACG draw up a value added income statement but I think that its application would be very useful to give evidence of the social value created".

As regards the operating grants, they are usually paid by public entities to supplement the difference between the market price and the price requested from the consumer. SEs sell their products and services at a lower price than the market price allowing to economically and socially weakest sections of the population purchase goods and services. The public entities intervene by providing operating grants if the activity of SEs is of general interest. The operation grants have been included in the production value even if they do not derive from exchange documents because they can be considered the prize for the social value created.

To comply the paper aim, other significant aspects were i) the correct interpretation of the item "other revenue" to exclude their attribution to revenue other than liberalities, and ii) the contribution of volunteers to the development of SEs. As Interviewee 2 points out:

"[S]ocial cooperatives joined to ACG group do not have any revenues other than those from sales and services, and the item other revenues refers to operating grants and to donations",

and continuing,

"[T]he contribution of volunteers is very significant in all SEs, but is not currently assessed (...) Volunteers brings new energy, motivations and pushes SEs to improve their business"

Volunteering above all but also donations have a strong impact on the economic sustainability of businesses. Nevertheless, the volunteers contribution is not currently evaluated essentially because the Italian tax legislation allows neither assessment nor budgetisation.

\section{Discussion and Conclusion}

The theoretical framework shows us that SEs can rely upon liberalities and volunteer workers. In fact, their social aim encourages people to support the activities by donating money and free time. What is the real state of the facts? Is there a sufficient/significant number of SEs that can count on this support? The empirical research says yes.

Data analysis revealed that in four cases there was a substantial break-even and a high incidence of donations (between 20 and 32 per cent of turnover). It follows that in the absence of donations, SEs would not have been economically sustainable. Only in three cases, very high incomes (over 250,000) correspond to a low incidence of donations (even it is not higher than $1 \%$ ).

The analysis of the financial statements of the 598 SEs, for which the data were available (primary sample), revealed that $40 \%$ of them receives liberalities. The internal documents showed that the $43 \%$ of the SEs investigated - for a total amount of 258 cases and a total of 2,628 volunteers involved as a whole - can rely upon the support of volunteers' work to achieve social goals. 
At this point, after that data and variables were grouped simultaneously on base on the two selected significant variables (liberalities and volunteers), a narrow cluster consisting of an amount of 239 SEs having both variables was obtained. In this restricted sample, a number of 204 SEs have achieved a ROE greater than zero. The high ROE observed (over 40\%) is a consequence of a low capitalization of the SEs in which the main productive factor is paid work. The same conclusion can be drawn by the IIS that highlights the significance of the value added attributed to the employees. The analysis of linear distribution of ROE shows that a large number of analysed SE generates potentially distributable income within the limits allowed by Italian law.

In the $3 \%$ of the cases observed, the impact of donations on turnover is significant and it ranges between 26 and $35 \%$ while in most cases it is irrelevant with a range between 1 and 5 percent. It is consistent with the characteristics of SEs in general. In $16 \%$ of the restricted sample SEs have a loss, in $35 \%$ of cases the economic result is positive but limited (less than 10,000 Euros). Volunteers are a relevant resource for SEs although their contribution to social value has been underestimated in this paper. The aim was to represent the role and significance of their economic and meta-economic contribution to company management (Mook et al., 2007), but it was preferred to limit the bias of the researcher and the subjectivity of the analysis. This value, as well as the donations received, contributes to the integrated value added which, for this reason, can never be distributed. Simple linear regression between number of employees and volunteers shows that the correlation between the volunteers and number of employees is significant for levels below 100 employees. From which it follows that the contribution of volunteers contributes more to the management of smaller entities.

The consolidated economic and social value was assessed in 416,543,142 Euros and following main conclusions can be taken from the IIS. Firstly, volunteering and donations produce value through activities of general interest carried out by the SEs. Secondly, without the contribution of both liberalities and volunteers, what appears to be a surplus would actually have been a loss. Additionally, the empirical research revealed that only the SEs with income higher have full economic self-sufficiency regardless of donations and the simple linear regression between net income and liberalities shows that the correlation between the donations received and the income is significant for levels below 200,000 Euros.

\subsection{Contribution}

The multiple case study approach allows have a broad observation base on the conditions of economic sustainability of the SEs and at the same time to detect the process of income formation of these hybrid organizations. Some important conclusions emerge from this study and given the size of the sample analyzed, they can be considered of general value. They contribute to SEs studies in the following aspects:

a) donations and volunteering are significant resources for SEs, especially for smaller ones. The most structured SEs, in terms of both employed and realized income, present a greater degree of economic self-sufficiency compared to free external resources;

b) according to the balance sheet data, the SEs seem economically sustainable. Instead, the assessment of the economic and social value through the IIS shows that both the economic sustainability of the SE and the development of the system as a whole are achieved thanks to free resources (donations and volunteering);

c) the value created by SEs can be expressed through the IIS. Regarding the latter, a novel perspective has been given to the usefulness of both donations and volunteering that enable SEs to contribute to mutual funds for the development of SEs (due to 3\% of net income) and to consolidate the equity usually greatly underpowered in the SEs - thanks to the provision of $30 \%$ of net profits required by law (column (a) of the IIS statement). The social value will produce further social development as it is intended directly or indirectly for activities of general interest;

d) the process of distribution of the economic and social value generated by the SEs emphasizes the share of this value which is not distributable. The latter represents the main contribution of this research. IIS emphasizes not only that the SEs create a greater value than the economic one (consisting of taxes, paid work, volunteer, interests, etc.), an aspect widely demonstrated in the literature, but also it avoids that by neglecting the direct contribution of the donations and the indirect contribution of volunteering to income, the SEs distributed profits not really achieved. This aspect is very important because according to Italian law the SEs can distribute the income produced (even if within certain limits).

\subsection{Originality and Value}

This study is novel because it not only analyses the social value created by SEs but focuses on the conditions of their economic sustainability. In this line, donations and volunteering allow SEs to: 
- direct valuable resources that otherwise would not be used or would be underused;

- consolidate the financial structure by increasing the internal sources of financing, thanks to the mandatory provisions in the no-distributable reserve;

- encourage the development through the consolidation of the economic system as a whole, thanks to the profits destined for mutual funds for the development of cooperation;

- improve their role in the economic system. SEs, as widely recognized also at European level, "contribute to important policy objectives, such as job creation, inclusiveness, equal opportunities, sustainability and civic participation. (...) They are an excellent example of an economy that works for people." (EU, 2020, p. 6).

This research can contribute to literature and practice as it fills existing gaps in the accounting process to determine the income produced by SE through extensive empirical research. This study focused on the "hybrid" characteristics of the SEs that allow them both to achieve social objectives (through the production and sale of goods and services) and to realize an income that can be distributed, under strict conditions, to shareholders. IIS offers another contribution. On the one hand, if it is necessary to avoid distributing, what appears to be income to shareholders, but actually it is only surplus obtained thanks to free resources, on the other hand, the taxes must be calculated on the actual wealth produced and theoretically distributable, excluding that share of the economic value to which the free resources contributed directly or indirectly. Finally, according to this line of thought, this document can provide suggestions to the government to better articulate both the support policies and the tax system for the SEs.

The limit of this research is that the measurement and evaluation of total value do not include the impact and the outcomes that are considered very important to evaluate the activity and social goals of the SEs (Manetti, 2014). In fact, the paper focuses only on data that can be deduced from the accounting system, on donations and on the contribution of volunteers. It was not considered the change generated by the activities carried out.

\subsection{Future Step of the Research}

This study presents aggregate data because one of its purpose is enhance the general awareness of the contribution that SEs offer in terms of both added value and the ability to channel free resources towards social purposes. The results offer interesting suggestions for future research. Firstly, separate IIS could be drawn up for each SE analysed in this study or in other researches to examine the relationships between the elements that form the whole.

Another step of the research could be to extend the analysis to other elements and variables that are not included at this stage. The change generated by the activities carried out and a more complex social accounting system could be taken into consideration, involving other variables and aspects (social impact, for example) to provide a clear representation of the effectiveness of SEs actions in a multidimensional and multi-stakeholder logic. Further step of the research could focus on the detailed comment of the economic data and include the financial analysis which has not been analysed in this paper because it is not directly inherent in the research purposes.

\section{References}

Adams, C. A., Muir, S., \& Hoque, Z. (2014). Measurement of sustainability performance in the public sector. Sustainability Accounting, Management and Policy Journal, 5(1), 46-67. https://doi.org/10.1108/SAMPJ-04-2012-0018

Anderberg, M. R. (1973). Cluster analysis for applications: probability and mathematical statistics: a series of monographs and textbooks. New York, NY: Academic press.

Andreaus, M., \& Costa, E. (2014). Toward an Integrated Accountability Model for Nonprofit Organizations. Accountability and Social Accounting for Social and Non-Profit Organizations. Advances in Public Interest Accounting, 17. Bingley, UK: Emerald Group Publishing Limited, 153-176. https://doi.org/10.1108/S1041-706020140000017006

Bagnoli, L., \& Megali, C. (2011). Measuring performance in social enterprises. Nonprofit and Voluntary Sector Quarterly, 40(1), 149-165. https://doi.org/10.1177/0899764009351111

Baldarelli, M. G., \& Del Baldo, M. (2018). Social Accounting in Italy: The Pioneering Contribution of Women Scholars. In Paoloni, P., \& Lombardi, R. (Eds.), Gender Issues in Business and Economics. Cham: Springer. https://doi.org/10.1007/978-3-319-65193-4_1

Baldarelli, M. G., Cosentino, A., Del Baldo, M., \& Magistro, A. (2018). Toward the Theory of Enterprise: Dialogue Between Business and Economics Women Scholars. Advances in Gender and Cultural Research in Business and Economics, 59-81, Springer, Cham. https://doi.org/10.1007/978-3-030-00335-7_5 
Ball, R., \& Brown, P. (1968). An empirical evaluation of accounting income numbers. Journal of accounting research, 6(2), 159-178. https://doi.org/10.2307/2490232

Bebbington, J., Gray, R., \& Owen, D. (1999). Seeing the wood for the trees: Taking the pulse of social and environmental accounting. Accounting, Auditing \& Accountability Journal, 12(1), 47-52. https://doi.org/10.1108/09513579910259906

Benos, T., Kalogeras, N., Wetzels, M., De Ruyter, K., \& Pennings, J. M. (2018). Harnessing a 'currency matrix' for performance measurement in cooperatives: A multi-phased study. Sustainability, 10(12), 4536. https://doi.org/10.3390/su10124536

Berg, B. L. (2007). Qualitative Research Methods for the Social Sciences. Long Beach, CA: Pearson Education,

Bontis, N., Ciambotti, M., Palazzi, F., \& Sgro, F. (2018). Intellectual capital and financial performance in social cooperative enterprises. Journal of Intellectual Capital, 19(4), 712-731. https://doi.org/10.1108/JIC-03-2017-0049

Borzaga, C., \& Defourny, J. (Eds.). (2001). The emergence of social enterprise. London: Routledge. https://doi.org/10.4324/9780203164679

Bowman, W. (2011). Financial capacity and sustainability of ordinary nonprofits. Nonprofit management and leadership, 22(1), 37-51. https://doi.org/10.1002/nml.20039

Brown, L. D., \& Moore, M. H. (2001). Accountability, strategy, and international nongovernmental organizations. Nonprofit and voluntary sector quarterly, 30(3), 569-587. https://doi.org/10.1177/0899764001303012

Clarke-Sather, A. R., Hutchins, M. J., Zhang, Q., Gershenson, J. K., \& Sutherland, J. W. (2011). Development of social, environmental, and economic indicators for a small/medium enterprise. International Journal of Accounting and Information Management, 19(3), 247-266. https://doi.org/10.1108/18347641111169250

Cosentino, A., Bongiovanni, L., Cesari, A., \& Di Stefano, C. (2017). Social Impact as an Intangible Driver in Assessing Economic Value: An Application to the Italian Third Sector. American Journal of Applied Sciences, December, 14(12). https://doi.org/10.3844/ajassp.2017.1152.1166

Crucke, S., \& Decramer, A. (2016). The development of a measurement instrument for the organizational performance of social enterprises. Sustainability, 8(161), 1-30. https://doi.org/10.3390/su8020161

Dal Mas, F., Massaro, M., Lombardi, R., \& Garlatti, A. (2019). From output to outcome measures in the public sector: a structured literature review. International Journal of Organizational Analysis, 27(5), 1631-1656. https://doi.org/10.1108/IJOA-09-2018-1523

De Villiers, C., Venter, E. R., \& Hsiao, P. C. K. (2017). Integrated reporting: background, measurement issues, approaches and an agenda for future research. Accounting \& Finance, 57(4), 937-959. https://doi.org/10.1111/acfi.12246

Deakin, S., \& Morris, G. (2012). UK: Labour law. Hart publishing.

Dees, J. G., \& Anderson, B. B. (2006). Framing a theory of social entrepreneurship: Building on two schools of practice and thought. Research on social entrepreneurship: Understanding and contributing to an emerging field, 1(3), 39-66.

Defourny, J., \& Nyssens, M. (2014). The EMES approach of social enterprise in a comparative perspective. Social enterprise and the third sector, 58-81. London: Routledge. https://doi.org/10.4324/9780203487747

Del Baldo, M. (2012). Corporate social responsibility and corporate governance in Italian SMEs: The experience of some "spirited businesses". Journal of Management and Governance, 16(1), 1-36. https://doi.org/10.1007/s10997-009-9127-4

Demartini, P., \& Paoloni, P. (2017). A Path Model "Why-What-How-When" to Implement an IC Reporting. International Journal of Business and Management, 12(6), 11-25. https://doi.org/10.5539/ijbm.v12n6p11

Doherty, B., Haugh, H., \& Lyon, F. (2014). Social enterprises as hybrid organizations: A review and research agenda. International Journal of Management Reviews, 16(4), 417-436. https://doi.org/10.1111/ijmr.12028

Dumay, J., \& Dai, T. (2017). Integrated thinking as a cultural control? Meditari Accountancy Research, 25(4), 574-604. https://doi.org/10.1108/MEDAR-07-2016-0067

Ebrahim, A., \& Rangan, V. K. (2014). What impact? A framework for measuring the scale and scope of social performance. California management review, 56(3), 118-141. https://doi.org/10.1525/cmr.2014.56.3.118 
Eisenhardt, K. M., \& Graebner, M. E. (2007). Theory building from cases: Opportunities and challenges. Academy of management journal, 50(1), 25-32. https://doi.org/10.5465/amj.2007.24160888

Elkington, J. (2013). Enter the triple bottom line. In The triple bottom line, 23-38. London: Routledge. https://doi.org/10.4324/9781849773348

Epstein, M. J., \& McFarlan, F. W. (2011). Measuring the efficiency and effectiveness of a nonprofit's performance. Strategic finance, 93(4), 27-35.

European Union. (2020) Social enterprises and their ecosystem in Europe. Comparative synthesis report. Luxembourg: Publications Office of the European Union. https://doi.org/10.2767/567551

Friedman, M. (1962). Capitalism and Freedom. Chicago: Chicago University Press.

Gabrovec, M. O. (2002). Bilancio sociale e valore aggiunto (translation Social report and added value), Hinna (ed), Il bilancio sociale. Scenari, settori e valenze (translation The social report. Scenarios, areas and values. Milano: Il Sole 24ORE, 359-396.

Gaskin, K. (1999). Valuing volunteers in Europe: A comparative study of the Voluntary Investment and Value Audit (VIVA). Voluntary Action: The Journal of Active Volunteering Research, 2(1), 35-48.

Giampaoli, D., Ciambotti, M., \& Bontis, N. (2017). Knowledge management, problem solving and performance in top Italian firms. Journal of Knowledge Management, 21(2), 355-375. https://doi.org/10.1108/JKM-03-2016-0113

Gray, R. (2002). The social accounting project and Accounting Organizations and Society Privileging engagement, imaginings, new accountings and pragmatism over critique? Accounting, organizations and society, 27(7), 687-708. https://doi.org/10.1016/S0361-3682(00)00003-9

Gray, R., Bebbington, J., \& Collison, D. (2006). NGOs, civil society and accountability: making the people accountable to capital. Accounting, Auditing \& Accountability Journal, 19(3), 319-348. https://doi.org/10.1108/09513570610670325

Gray, R., Owen, D., \& Adams, C. (1996). Accounting and accountability: Changes and challenges in corporate social and environmental reporting. London: Prentice Hall.

GRI. Global reporting initiative (2018). Retrieved February 2, 2020, from https://www.globalreporting.org/standards/

Grieco, C. (2015). Assessing social impact of social enterprises: Does one size really fit all? Cham: Springer. https://doi.org/10.1007/978-3-319-15314-8

Grimsey, D., \& Lewis, M. K. (2005). Are public private partnerships value for money? Evaluating alternative approaches and comparing academic and practitioner views. Accounting Forum, 29(4), 345-378. https://doi.org/10.1016/j.accfor.2005.01.001

Guidi, R., Cappadozzi, T., \& Fonovic, T. (2016). Volontari e attività volontarie in Italia. Antecedenti, impatti, esplorazioni, 5-359. Bologna: Il Mulino.

Handy, F., Mook, L., \& Quarter, J. (2008). The interchangeability of paid staff and volunteers in nonprofit organizations. Nonprofit and Voluntary Sector Quarterly, 37(1), 76-92. https://doi.org/10.1177/0899764007303528

Hansmann, H. B. (1980). The role of nonprofit enterprise. The Yale law journal, 89(5), 835-901. https://doi.org/10.2307/796089

Hopwood, A. G. (2009). Reflections and projections-and many, many thanks. Accounting, Organizations and Society, 34(8), 887-894. https://doi.org/10.1016/j.aos.2009.08.002

Jervis, M. G., \& Drake, M. (2014). The use of qualitative research methods in quantitative science: A review, Journal of Sensory Studies, 29(4), 234-247. https://doi.org/10.1111/joss.12101

Kerlin, J. A. (Ed.) (2009). Social enterprise: A global comparison. USA: Tufts University Press.

La Torre, M., Sabelfeld, S., Blomkvist, M., Tarquinio, L., \& Dumay, J. (2018). Harmonising non-financial reporting regulation in Europe: Practical forces and projections for future research. Meditari Accountancy Research, 26(4), 598-621. https://doi.org/10.1108/MEDAR-02-2018-0290

Larrinaga-González, C., \& Bebbington, J. (2001). Accounting change or institutional appropriation? A case study of the implementation of environmental accounting. Critical Perspectives on Accounting, 12(3), 269-92. https://doi.org/10.1006/cpac.2000.0433 
Lehman, C. R. (1995). Accounting's changing role in social conflict. New York: Markus Wiener Publishers.

Lewis, L., \& Unerman, J. (1999). Ethical relativism: a reason for differences in corporate social reporting? Critical Perspectives on Accounting, 10(4), 521-547. https://doi.org/10.1006/cpac.1998.0280

Manetti, G. (2014). The role of blended value accounting in the evaluation of socio-economic impact of social enterprises. VOLUNTAS: International Journal of Voluntary and Nonprofit Organizations, 25(2), 443-464. https://doi.org/10.1007/s11266-012-9346-1

Mook, L., \& Quarter, J. (2006). Accounting for the social economy: The socioeconomic impact statement. Annals of Public and Cooperative Economics, 77(2), 247-269. https://doi.org/10.1111/j.1370-4788.2006.00305.x

Mook, L., Handy, F., \& Quarter, J. (2007). Reporting volunteer labour at the organizational level: A study of Canadian nonprofits. Voluntas: International Journal of Voluntary and Nonprofit Organizations, 18(1), 55. https://doi.org/10.1007/s11266-007-9030-z

Mook, L., Richmond, B. J., \& Quarter, J. (2003). Integrated social accounting for nonprofits: A case from Canada. Voluntas: International journal of voluntary and nonprofit organizations, 14(3), 283-297. https://doi.org/10.1023/A:1025614619742

Mook, L., Richmond, B. J., \& Quarter, J. (2009). Calculating the value of volunteer contributions for financial statements. The Philanthropist, 18(1), 71-83.

Mook, L., Sousa, J., Elgie, S., \& Quarter, J. (2005). Accounting for the value of volunteer contributions. Nonprofit Management and Leadership, 15(4), 401-415. https://doi.org/10.1002/nml.79

Nicholls, A. (2009). 'We do good things, don't we?': 'Blended Value Accounting' in social entrepreneurship. Accounting, organizations and society, 34(6-7), 755-769. https://doi.org/10.1016/j.aos.2009.04.008

Parker, L. D. (2005). Social and environmental accountability research: a view from the commentary box. Accounting, Auditing \& Accountability Journal, 18(6), 842-60. https://doi.org/10.1108/09513570510627739

Patton, M. Q. (1990). Qualitative evaluation and research methods. Thousand Oaks, CA: Sage.

Peredo, A. M., \& McLean, M. (2006). Social entrepreneurship: A critical review of the concept. Journal of world business, 4l(1), 56-65. https://doi.org/10.1016/j.jwb.2005.10.007

Pollifroni, M. (2012). Environmental sustainability and social responsibility: a theoretical proposal for an accounting evaluation. Economia Aziendale Online, 2(4), 345-354.

Pollifroni, M. (2013). Ethical Ratings: A Systematic Analysis Oriented to Business Economics. Procedia Economics and Finance, 6, 342-352. https://doi.org/10.1016/S2212-5671(13)00148-2

Pollifroni, M. (2017). L'Etica Aziendale nei Processi di Globalizzazione dei Mercati. Paradigmi, Determinanti, Valutazioni, (translations Business Ethics in the Globalization of Markets Processes. Paradigms, Determinants, Evaluations), Vol. 71, Turin: Giappichelli.

Porter, M. E., \& Kramer, M. R. (1999). Philanthropy's new agenda: creating value. Harvard Business Review, 77(6), 121. Retrieved from https://hbr.org/1999/11/philanthropys-new-agenda-creating-value

Quarter, J., Mook, L., \& Richmond, B. J. (2003). What Counts: Social Accounting for Nonprofits and Cooperatives. Toronto: Prentice Hall.

Richmond, B. J., Mook, L., \& Jack, Q. (2003). Social accounting for nonprofits: Two models. Nonprofit management and leadership, 13(4), 308-324. https://doi.org/10.1002/nml.2

Salamon, L. M., \& Anheier, H. K. (1996). The international classification of nonprofit organizations: ICNPO-Revision, 1. Baltimore Mar: Johns Hopkins University Institute for Policy Studies.

Spencer, L., \& Ritchie, J. (2002). Qualitative data analysis for applied policy research. Analyzing qualitative data, 187-208. London: Routledge. https://doi.org/10.4324/9780203413081

Stake, R. E. (2013). Multiple case study analysis. New York, NY: Guilford Press.

Unerman, J., Bebbington, J., \& O’Dwyer, B. (2010). Introduction to sustainability accounting and accountability. Sustainability accounting and accountability, 20-35. London: Routledge.

Urban, B. (2015). Evaluation of social enterprise outcomes and self-efficacy. International Journal of Social Economics, 42(2), 163-178. https://doi.org/10.1108/IJSE-03-2013-0071

Warheit, G. J., Buhl, J. M., \& Bell, R. A. (1978). A critique of social indicators analysis and key informants surveys as needs assessment methods. Evaluation and program planning, 1(3), 239-247. https://doi.org/10.1016/0149-7189(78)90079-4 
Yin, R. K. (2014). Case Study Research: Design and Methods. Thousand Oaks, CA: SAGE. .

Young, D. R., \& Salamon, L. M. (2002). Commercialization, social ventures, and for-profit competition. In Salomon L. M. (Ed.), The state of nonprofit America, 423-446. Washington, D.C.: Brooking Institution Press.

Young, D. R., (2013). If Not for Profit, for What? (1983 Print Edition) Faculty Books. 1. Retrieved from https://scholarworks.gsu.edu/facbooks2013/1

\section{Copyrights}

Copyright for this article is retained by the author(s), with first publication rights granted to the journal.

This is an open-access article distributed under the terms and conditions of the Creative Commons Attribution license (http://creativecommons.org/licenses/by/4.0/). 